This item was submitted to Loughborough's Research Repository by the author.

Items in Figshare are protected by copyright, with all rights reserved, unless otherwise indicated.

\title{
Connecting heritage, vulnerabilities and capacities through a participatory game
}

\section{PLEASE CITE THE PUBLISHED VERSION}

https://doi.org/10.1016/j.ijdrr.2020.102005

\section{PUBLISHER}

Elsevier

\section{VERSION}

AM (Accepted Manuscript)

\section{PUBLISHER STATEMENT}

This paper was accepted for publication in the journal International Journal of Disaster Risk Reduction and the definitive published version is available at https://doi.org/10.1016/j.ijdrr.2020.102005.

\section{LICENCE}

CC BY-NC-ND 4.0

\section{REPOSITORY RECORD}

Chmutina, Ksenia, Aparna Tandon, Maryam Kalkhitashvili, Manana Tevzadze, and Irakli Kobulia. 2020. "Connecting Heritage, Vulnerabilities and Capacities Through a Participatory Game". Loughborough University. https://hdl.handle.net/2134/13317284. 


\title{
UNDERSTANDING THE INTERCONNECTION OF CULTURAL HERITAGE, VULNERABILITIES, AND CAPACITIES PARTICIPATION
}

Ksenia Chmutina ${ }^{* 1}$, Aparna Tandon ${ }^{2}$, Maryam Kalkhitashvili $^{3}$, Manana Tevzadze $^{3}$, Irakli Kobulia $^{3}$

${ }^{* 1}$ Corresponding Author: School of Architecture, Building and Civil Engineering, Loughborough University, Loughborough, UK, LE11 3TU. Email: k.chmutina@Iboro.ac.uk

${ }^{2}$ The International Centre for the Study of the Preservation and Restoration of Cultural Property (ICCROM), Rome, Italy

${ }^{3}$ Georgian National Committee of the Blue Shield, Tbilisi, Georgia

\begin{abstract}
Cultural heritage is not only seen as a sector that needs protecting in times of a disaster but also as a source of strengths for the communities and individuals. There is however very little understanding on the actual contributions of cultural heritage towards capacity development; little is also known about cultural heritage as a potential source of vulnerability. Based on a case study of the Racha region in Georgia, this paper explores the potential role of heritage through the lens of vulnerabilities and capacities as understood by the local people, and presents the views of the local population on their cultural heritage. It demonstrates that tangible and intangible dimensions are intertwined and highlights that cultural heritage cannot be seen in an exclusive manner devoid of its larger environmental, political, social and economic contexts if we are to understand the relationship between cultural heritage, capacities and vulnerabilities.
\end{abstract}

Key words: cultural heritage, vulnerability, capacities, participatory research, Georgia

\section{Introduction}

The vast range of heritage is increasingly exposed - and is gradually lost - to various natural and human induced hazards such as earthquakes, floods, fires, hurricanes, landslides, terrorism and armed conflicts all around the world. Fragility of historic fabric and higher vulnerability (due to ageing materials, limited critical infrastructure for emergency and urban density), the increasing pressures in urban areas due to the geo-physical environment, carrying capacity and socio-economic developments, as well as many other factors increase vulnerability of cultural heritage (Jigyasu, 2016). Besides the loss to the material fabric, disasters also affect intangible heritage including traditional knowledge, practices, skills and crafts that ensure continuity of living cultural heritage as well as means for its maintenance and conservation (Chmutina et al., 2019). The loss of tangible and intangible cultural heritage affects cultural and social values; this has triggered a large shift towards understanding and highlighting the role of cultural heritage in disaster risk reduction (DRR) and sustainable development (Boccardi and Duvelle, 2013; UNESCO, 2017).

What is however missing in much of the debate is the deeper engagement with communities who live with and are sustained through cultural heritage. Here we adapt an important question posed by Schipper (2015): Do culture and heritage exacerbate social vulnerabilities, or are they a source for resilience? The answer is unclear because cultural heritage is still mainly seen as a resource-consuming sector that needs protecting in times of a disaster. Our understanding of the role that cultural heritage could play in reducing risks is rudimentary and requires further evidence. Based on a case study of Racha region in Georgia, this paper explores the potential role of heritage through the lens of vulnerabilities and capacities as understood by the local people, and presents the views of the local population on their cultural heritage. We will first reflect on cultural heritage in the context of development; we 
will then introduce the case study region and methodology and proceed to discuss our findings.

\section{What is cultural heritage?}

In the past decades, the notion of cultural heritage has expanded interminably. From physical or tangible manifestations of the past, such as monuments, archaeological sites or objects in museums, the idea of heritage has expanded to include immaterial manifestations of cultures, such as traditions, knowledge systems, traditional practices or performing arts and other creative expressions, collectively termed as 'intangible heritage'.

Key International statements such as the Nara Declaration on Authenticity, the Tokyo declaration on heritage and cultural diversity (2000), and the two UNESCO conventions (namely, the Convention for the Safeguarding of the Intangible Heritage (2003), and the Convention on the Protection and Promotion of the Diversity of Cultural Expressions) have helped in expanding the concept of heritage by highlighting the aspects of diversity and immateriality in the international heritage discourse as well as in the public policy domain (Simpson, 2018)

The idea of cultural heritage has been expanded even further by including natural environment. The UNESCO Convention concerning the Protection of World Cultural and Natural Heritage (1972) was introduced to acknowledge the age-old relationship between people and their natural environment, which is expressed through their traditions and rituals (Isar, 2011). As UNESCO underscores: "By regarding heritage as both cultural and natural, the Convention reminds us of the ways in which people interact with nature, and of the fundamental need to preserve the balance between the two" (UNESCO, n.d.). Famous natural cultural heritage sites including the Cliffs of Bandiagara in Mali or Great Barrier Reef in Australia.

\subsection{Cultural Heritage in Sustainable Development and DRR}

Tangible heritage has been perceived for a long time as in need of safeguarding. This "do not harm the heritage" approach seeks to minimise damage and reduce any adverse impacts of development on cultural heritage sites (World Bank, 2001). The actions specified for staff as well as clients included: a) move project activities; b) modify project design to include concerns for the protection of heritage structures; c) failing all else, in consultation with state authorities, relocate cultural property to another site. Action c, whilst taken rarely, happens nevertheless: for instance, in 1968 the Egyptian temple of Abu Simbel was relocated in order to build the Aswan high dam. Whilst it is widely accepted as a norm, safeguarding remains a challenge, especially in rapidly urbanising, emerging economies, where it continues to be threatened by large-scale development projects (Winter and Daly, 2012).

In the recent decades, however, there has been a significant shift in the perception of cultural heritage and the role it plays in sustainable development . . In 1999, the World Bank outlined a framework of action for culture in development, which proclaimed its intent to go beyond safeguarding cultural heritage in order to capture its economic potential. The aim was to utilise heritage safeguard for reducing poverty and generating livelihoods. The economic value of heritage and its potential to educate formed the cornerstone of the World Bank's framework (The World Bank, 2001). And indeed, the economic contributions of cultural heritage are significant. In its 2018 monitoring report on Creative Europe, the Directorate-General for Communications Networks, Content and Technology of the European Commission (p. 8) confirms that "the cultural and creative sectors represent a significant share of the EU economy (over $4 \%$ of EU GDP) and provide quality jobs (6.7 million jobs) especially for young people." 
Ten years on, the role of heritage in sustainable development is clearly acknowledged in the public policy domain. For example, Goal 11 of the 2030 Agenda for Sustainable Development stresses the need to "make cities and human settlements inclusive, safe, resilient and sustainable" and, in Target 11.4, acknowledges the importance of strengthening "efforts to protect and safeguard the world's cultural and natural heritage"(UNGA 2015, p. 22). Moving beyond sites and built heritage, governments are increasingly recognising the potential of other cultural and creative industries such as crafts, visual arts, theatre, TV, radio, music, new media and so on. The role of cultural heritage has therefore been gradually evolving from a passive 'recipients' of safeguarding to an active contributor to development.

It is also important to note the role of cultural heritage in disasters and conflicts. Cultural heritage has been gradually recognised by the international community as not just sites that require protection but as important socio-political actants. The role of cultural heritage as a means of capacity has been widely discussed in disaster studies literature (Pareek and Trivedi, 2011; Miichi, 2016). Here we used the UNDRR's (2018) definition of capacity: "the combination of all the strengths, attributes and resources available within an organization, community or society to manage and reduce disaster risks and strengthen resilience". It emphasises that capacity is not just about the availability of resources and highlights that the potential of communities themselves to play a central role in dealing with disaster risk should not be underestimated. This potential is often founded on cultural and traditional practices and relationships.

Recognising the significance of cultural heritage for war torn communities, in 2016 the United Nations Human Rights Council through its resolution 33/20 on cultural rights recognised that destruction of cultural heritage undermines the rights of associated people and prevents them from enjoying their cultural life (UNHRC, 2016). A year later, the United Nations Security Council (2017) adopted a landmark resolution 2347 that linked deliberate destruction of cultural property and its illicit trade as a deterrent to world peace.

In disaster risk reduction, the role of cultural heritage has also been progressively documented in research and policy documents. It is widely acknowledged that traditional knowledge systems embedded in cultural heritage could help in preparing for and mitigating disaster risks. Traditional knowledge informs capacities that allow avoiding an occurrence of a hazard. For instance, traditional construction systems taq (timber-laced masonry) and dhajji dewari (timber frame with masonry infill) used in Kashmir that have proven to be effective in surviving the impacts of earthquakes (Lagenbach, 2009). Traditional stories played an important role for some communities during the Indian Ocean Tsunami in December 2004. For example, the Moken community in Thailand knew the signs such as unusual behaviour of animals, birds and low tide as indications for a tsunami from their traditional stories. This allowed the community to move away from the sea towards protective areas (Arunotai, 2008). Heritage safeguard is a powerful tool for providing psycho-social recovery. As highlighted by Daisuke (2020), in the aftermath of the 2011 earthquake and Tsunami, the affected communities in the Miyagi prefecture found solace in salvaging historic documents held by private collections. The recovery of the private records and historical documents provided a connection with the past as well as a sense of identity for those who were relocated to transitional shelters.

The UN's Sendai Framework for Disaster Risk Reduction (SFDRR) 2015-2030 has formally acknowledged the need to include cultural heritage in disaster risk reduction through Priorities for Actions: Priority Area 1 calls "(d) To systematically evaluate, record, share and publicly account for disaster losses and understand the economic, social, health, education, environmental and cultural heritage impacts, as appropriate, in the context of event-specific hazard-exposure and vulnerability information"; in Priority Area 3, point (d) declares that in order to achieve effective public and private investments in disaster risk prevention and reduction for resilience, it is important: "To protect or support the protection of cultural and 
collecting institutions and other sites of historical, cultural heritage and religious interest" (UNDRR, 2015).

However, whilst the positive role of cultural heritage in conflict and disasters is important, it should not be romanticised. Evidence suggests that heavy reliance and inability/ unwillingness to break away from traditions and culture can increase people's vulnerability (e.g. Lavigne et al, 2008). Here we will again use the UNDRR's (2018) definition of vulnerability: "the conditions determined by physical, social, economic and environmental factors or processes which increase the susceptibility of an individual, a community, assets or systems to the impacts of hazards". This definition is problematic and requires a consideration of how these conditions come to be - and why some individuals and communities are more susceptible than others (Bankoff, 2001; Cannon, 2008), as will be reflected later in the paper.

Whilst traditional practices can help dealing with frequent flooding, it is not enough to build a large dike to prevent a long-term flooding. Moreover, in some cases, traditional knowledge and practices can even increase vulnerability: deeply rooted discriminatory socio-cultural values and traditions exclude some community groups from participation. Religious beliefs and traditional social systems such as the caste system in India, have contributed to deep rooted inequalities, which make marginalised populations more vulnerable to hazards (Crabtree, 2015; Jones and Boyd, 2011). Cultural heritage can also be a tool for furthering conflict ideologies or for carrying out acts of 'cultural cleansing' such as the deliberate destruction of Palmyra and other iconic heritage sites by Islamic State of Iraq and the Levant (ISIL, also known as ISIS). Whilst the term 'cultural cleansing' was first used by the former Director-Gereneral of UNESCO, Irina Bokova, is not a legally used, nonetheless, it underscores the fact that heritage can be used a weapon of war to intensify hostilities (Weiss and Connelly, 2017).

\subsection{The missing elements of cultural heritage discourse}

As noted in the previous section, the processes of organising, preserving as well as marketing heritage have a huge potential for sustainable development, as they help to create jobs, educate others, and enhance well-being. Yet, the expert-centric, European Authorised Heritage Discourse (AHD) propagated by UNESCO Conventions, gives the power and legitimacy of recognising as well as managing the heritage of a group or a community to international experts and individual state parties (Smith, 2006). According to Smith (2015 p.135), 'AHD privileges aesthetically pleasing material objects, sites, places and/or landscapes. Their fragility requires that current generations must care for, protect and venerate these things so that they may be inherited by future generations. Within this framework heritage is something that is 'found', it has an innate value, the authenticity of which that will 'speak' to a common and shared sense of human identity. This understanding of heritage became entangled with discourses of nationhood, citizenship and nationalism.'

This Eurocentric understanding of heritage has systematically prevented marginalised groups from participating in how their heritage is recognised, valued or managed, leading to dissonance and conflict. More often than not, nationalised discourses tell stories that fail to capture the world views of subaltern groups. Moreover, a community's understanding of heritage may not be the same as that offered by professional AHD, which lays emphasis on material culture fixed in time and place, whereas for people intangible associations expressed in rituals or practices may hold more significance (Smith, 2015). Think, for instance, of the destroyed Buddhas' statues of Bamiyan Valley in Afghanistan. In the Hazaras (local minority population) folklore, the statues represent the love story of low-born hero, Salsal, who fell in love with a princess called Shahmama. According to Kavita Singh $(2015$, p. 46), "the story knits the two Buddhist sculptures together with environmental elements - the dragon rock, the dam on the lake - making them part of the Bamiyan landscape". Whereas the criteria for 
outstanding universal value of the Cultural Landscape and Archaeological Remains of Bamiyan Valley, as inscribed on the World Heritage list, describe it as a "monumental expression of western Buddhism' (UNESCO, n.d.). Moreover, from an international perspective, the cultural tradition of the central Asian region seems to have disappeared from the Bamiyan Valley, which is in direct opposition to the views held by the local Hazaras. Its value is therefore decided by those with more authority.

Recognising this disparity, a growing body of literature points out to the need to engage local and in particular, marginalised, populations in defining meanings as well as possible uses of heritage (Chinyele and Lwoga, 2019). Influenced by the discourse around sustainability, there is also a growing recognition within the heritage conservation policies, to go beyond the nature-culture divides and develop holistic perspectives that seek to achieve balance between development and conservation (Winter and Daly, 2012). Nonetheless, there are still noticeable gaps between policy and practice, as communities that may have valuable insights and traditional knowledge remain excluded from decision-making for conservation of their habitats. For example, in May 2020 super cyclone Amphan affected the two World Heritage sites of Sundarbans divided by a border between India and Bangladesh. The mangroves forests of Sundarbans consist of a unique ecological system known for its rare flora and fauna. The mangroves themselves provide a protective barrier against frequent cyclones and storm surges. Yet the delicate ecological system is threatened due to several upstream developments both in India and Bangladesh. The forest dwellers, who live on the edge of the World Heritage sites have knowledge inherited from generations, which could be valuable for safeguarding this unique habitat. Yet, top down policies have marginalised these forest dwellers, and they are seen as a 'threat' to the delicate ecosystem of the Sundarbans. Arguments have been made to develop policies that encourage 'transformative humannature interactions' and move towards using the knowledge held by the locals to conserve the mangrove forests and the nature reserves (Titumir et al. 2020) - but in practice, this has not yet taken place.

Breaking away from the mainly Western and material-based conceptualisation of heritage, various attempts have been made, in post-colonial countries, particularly those in Asia, to engage communities in defining as well as conserving their heritage. Yet, the antiquated topdown national systems for cultural protection in such countries link cultural governance with the idea of nationalism, and are therefore, inconsistent with bottom-up approaches needed for community participation. As Lloyd (2012) suggests, this is especially true when the protection measure may involve expression of cultural identity or ownership of cultural rights or for that matter participation in managing natural resources.

Communities are never homogenous: the information asymmetries and unequal distributions do not only exist between a community and other political actors, but also within the community (Pelling, 1998). The idea of heritage is thus closely linked to the inherent power relations in the community. Chmutina et al. $(2019$, p.7) highlight that 'it would be pertinent to ask whether vulnerability and risk reduction of one aspect of heritage is not at the expense of heritage belonging to the weak and marginalised'. Marginalisation is an issue in cultural heritage, and by claiming to engage with the 'community', the issues of power, donors and leadership - and the impacts of these issues on deciding whose heritage is protected by whom and how- become hidden. In the light of the above discussion, this paper explores how and whether a participatory mapping of vulnerabilities and capacities of cultural heritage can provide a way for a community to discuss their collective and separate identities that stem from heritage. Disaster risk provides a context which encourages people to think about their capacities and vulnerabilities, thus the framing of the paper. Here we attempt to go beyond the Authorised Heritage Discourse and instead amplify the voices of those living with and within the cultural heritage. 


\section{Setting the context - brief overview of Georgia}

Georgia ranks $70^{\text {th }}$ on the Human Development Index (UNDP, 2018). The main sectors of the country's economy are trade, industry, public administration, transport and communication, and agriculture. In past years, tourism has also become one of the priority sectors (IBP, Inc, 2012). Georgia has a rich tangible and intangible heritage: while the majority of its listed sites amount to medieval ecclesiastic architecture, the diversity of geography, ethnic, cultural and religious values is also important.

A substantial part of Georgia's population still lives in poverty, with disparities especially prominent in rural areas, with limited access to basic services and political and social engagement (WBG, 2016). The most pressing issues are inadequate housing conditions and high levels of unemployment; these have been exacerbated by the armed conflicts in the 1990s in South Ossetia and Abkhazia and the 2008 Georgian-Russian war.

\subsection{Disaster risks in Georgia}

Georgia is located in the South Caucasus region, between the Black sea to the west and Caucasus mountains to the north. $80 \%$ of the territory is mountainous and, due to its complex geological and diverse geomorphological, hydrological, climatic and geo-botanical conditions, it is highly exposed to a wide range of natural hazards (Varazanashvili et al., 2012). Georgia is situated in one of the most seismically active regions in the Alpine-Himalayan collision belt. Strong earthquakes, such as the Racha earthquake in 1991, with 7 magnitude, resulting in 250 fatalities and approximately USD 3 billion in damage, have occurred in the region. (GFDRR, 2015). Floods are also very frequent, with recorded high-water levels during the spring and summer months, when snow starts to melt. Over $50 \%$ of the national territory is prone to avalanches. Debris flows and mudslides present a high risk to the majority of the population in mountainous areas, especially those residing along small rivers (UNDP, 2014).

\subsection{Racha regional profile}

Racha is a historical province in Georgia's north-western mountainous region, and a part of the administrative region of Racha-Lechkhumi and Kvemo Svaneti (Lower Svaneti) (Fig. 1). With the total area of 2,893 $\mathrm{km}^{2}$, Racha is the least populated region of Georgia with 29,700 people (Topchishvili, 2010).

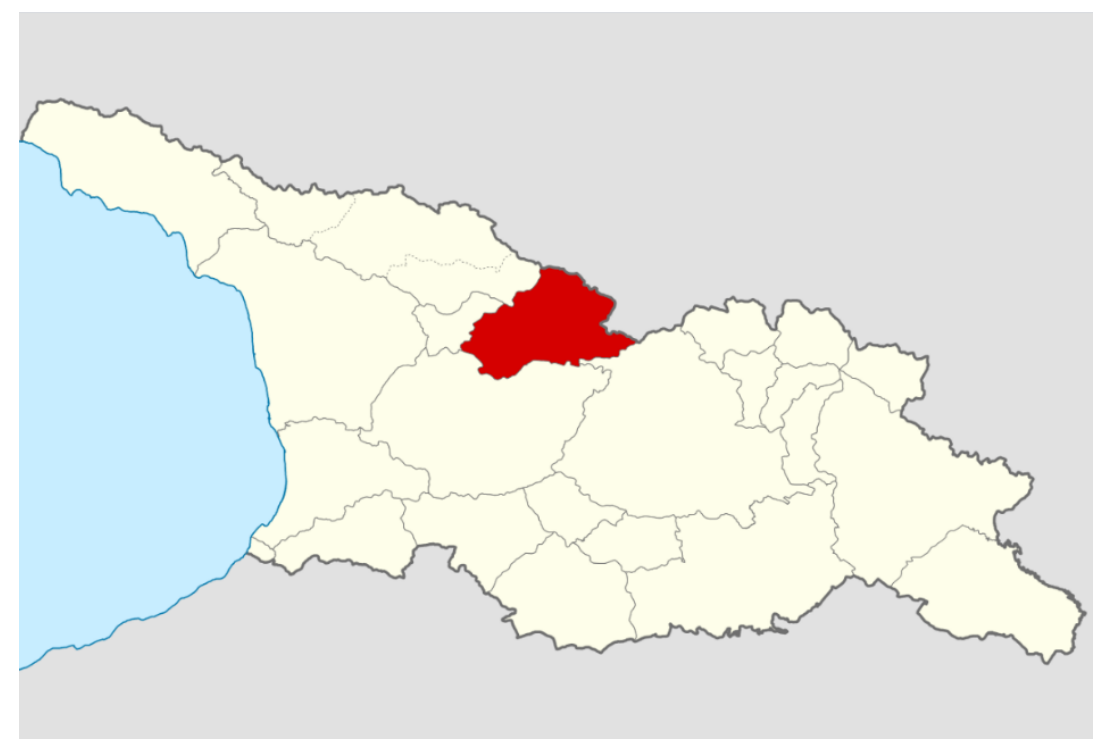

Figure 1 Location of Racha (Source: Google Maps)

It is one of the most hazard-prone regions in Georgia, regularly affected by mudflows, landslides and floods, as well as strong seismic activity. The region has limited access to 
healthcare and education, poor conditions of access roads in many communities, low income as well as lower education levels and access to information. The lack of adequate land use planning results in the concentration of the population, infrastructure and economic assets in hazardous areas (Racha Lechkhumi, 2013). Demographic profile of the region is also changing dramatically as the population is declining due to migration and ageing: since 1994 the population of the administrative region has declined by $51.7 \%$ (Kohler et al., 2017),

The region is well known for wood carving, blacksmithing and medieval fortifications and ecclesiastic structures with highly decorative rendering of bas reliefs and murals. But these (and other crafts) are declining as the population is ageing and migrating. The remaining examples of traditional dwellings (Fig. 2) require preservation - as is the traditional knowledge of their construction and decoration. Traditional form of agriculture that is still alive and contributes to the livelihood of the region is winemaking.

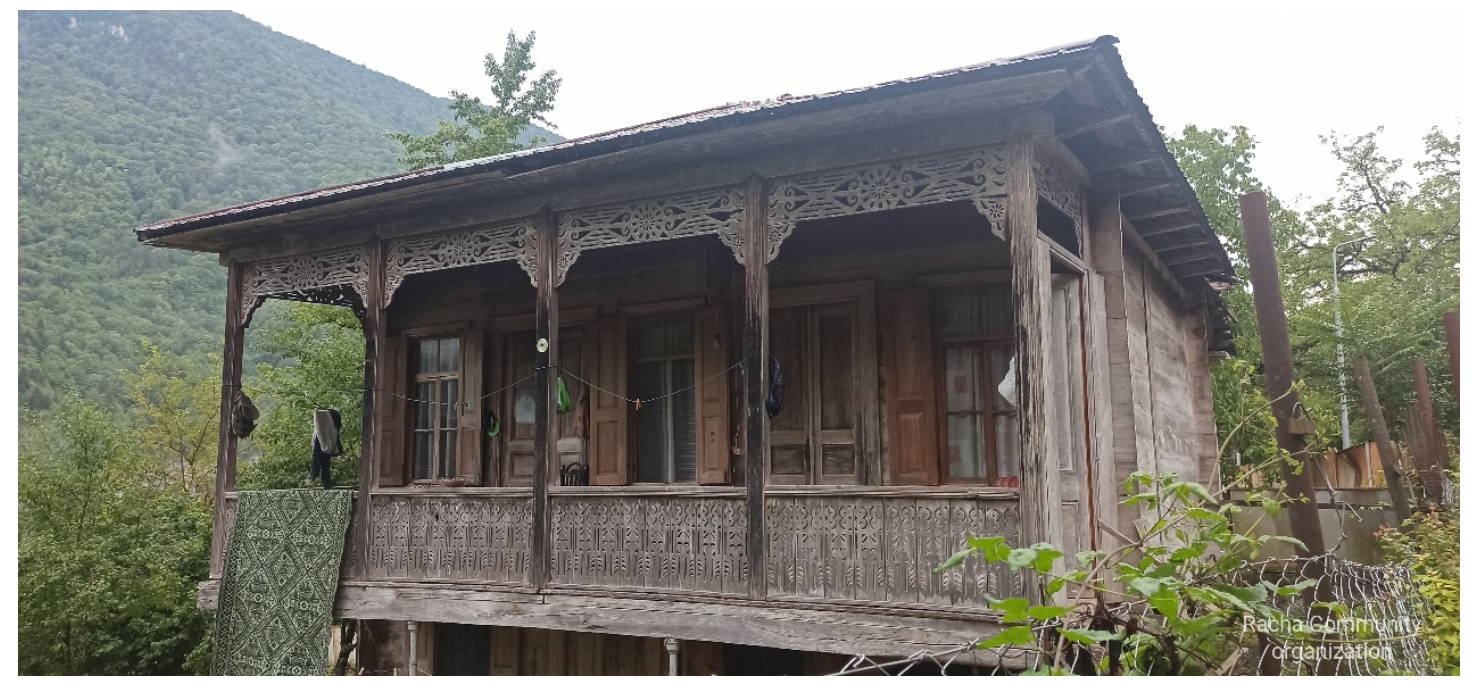

Figure 2 An example of a traditional wooden architecture in Racha region (authors' image)

\section{Methodology}

In order to understand how the local people view the role of cultural heritage in their lives, the vulnerabilities it increases and the capacities it provides, the research has been framed as a Vulnerability and Capacity Assessment (VCA) using a participatory game approach. VCA is a common tool used by international and local NGOs in disaster risk reduction practice. It allows looking at vulnerabilities and capacities at the same time, presenting opportunities for strengthening - in terms of the impact of a disaster on the physical, social, and attitudinal element of life. The objectives of a VCA are typically to aid a community exposed to various hazards to identify the hazards that affected them, categorise their vulnerabilities, and map out their capacities, in order to engage in developing a DRR plan and disseminate the results among the relevant stakeholders (Winser, 2016).

Here we use participatory mapping as our aim was to not only understand the vulnerabilities and capacities of the communities, but to also identify the most salient elements of cultural heritage to these communities and its role in creating vulnerabilities and capacities. It also allowed us not to treat the participants as passive recipients of 'research', but bring them into the idea generation process itself, informing the outcomes The participatory mapping confers power to people, demonstrating their perception of not only the locality and risks but also their relation with services, products, policies or even everyday tasks - and in our case, cultural heritage (Cadag and Gaillard, 2014; Gaillard et al., 2015). Through providing an informal and playful but culturally sensitive way of engagement, we encouraged active participation from the community. 
The data was collected in two municipalities of the region Racha (specifically in the towns of Ambrolauri and Oni) between $28^{\text {th }}$ of July and $2^{\text {nd }}$ of August 2019. Prior to commencing the data collection, the team examined the key terminology to ensure that the questions reflect the intended meaning but are translating well into Georgian language. The rules for the exercises and guiding questions were developed collaboratively first in English, then translated into Georgian and back-translated and piloted to ensure robust common questions were used. All data collection was carried out in Georgian by three of the co-authors (who are also Georgian).

The data has been collected in two stages ${ }^{1}$. The first stage comprised of participatory mapping exercise (Chambers, 2017); each session lasted between three to four hours, with four groups representing different sections of society:

- Local authority (divided into three groups) comprising 15 participants (7 male and 8 female);

- Volunteers and local NGOs' workers (divided into two groups) comprising 9 participants ( 7 male and 2 female);

- Craftspeople (including wood workers, textile workers, artists, poets) (divided into two groups), comprising 9 participants ( 5 male and 4 female);

- Farmers and wine makers, comprising 9 participants ( 5 male and 4 female).

Whilst we appreciate that some of the participants may represent two or more sections, their allocation into a certain group has been based on their primary daily activities (as described by them).

Facilitated by one of the local co-authors, the participants in each group were asked to map out the four following elements:

1. Tangible, intangible and natural heritage (i.e. objects, places and activities that have cultural value and that make this region and the participants distinctive);

2. Risks ${ }^{2}$ (i.e. what threatens one's livelihood and cultural heritage) and the sources of risks ${ }^{3}$;

3. Strengths ${ }^{4}$ (both in people and cultural heritage) that help coping/mitigating the risks

4. Governmental programmes that have an impact on cultural heritage and livelihood in the region.

The scale of maps was chosen by each group and ranged from a specific village (e.g. Ghebi village) to an area of a region (e.g. Upper Racha). A wide range of stationary and crafts' materials has been provided for mapping, including plastic and wooden building blocks, playdough, colouring pencils and marker pens, colourful paper, stickers, wooden blocks and so on. The participants were asked to decide how these materials will be used and what they would represent (see Fig. 3: on these maps four groups used Upper Racha as their scale).

\footnotetext{
${ }^{1}$ The game manual developed as a result of this project describes the rules of the exercise in detail, and is publicly available here: https://www.iccrom.org/news/insight-participatory-game-enhancingdisaster-risk-governance

${ }^{2}$ Risk, hazard and threat are the same word when translated into Georgian

3 The term 'vulnerability' was intentionally avoided due to its contested and academic nature

4 The term 'capacities' was intentionally avoided due to its contested and academic nature.
} 

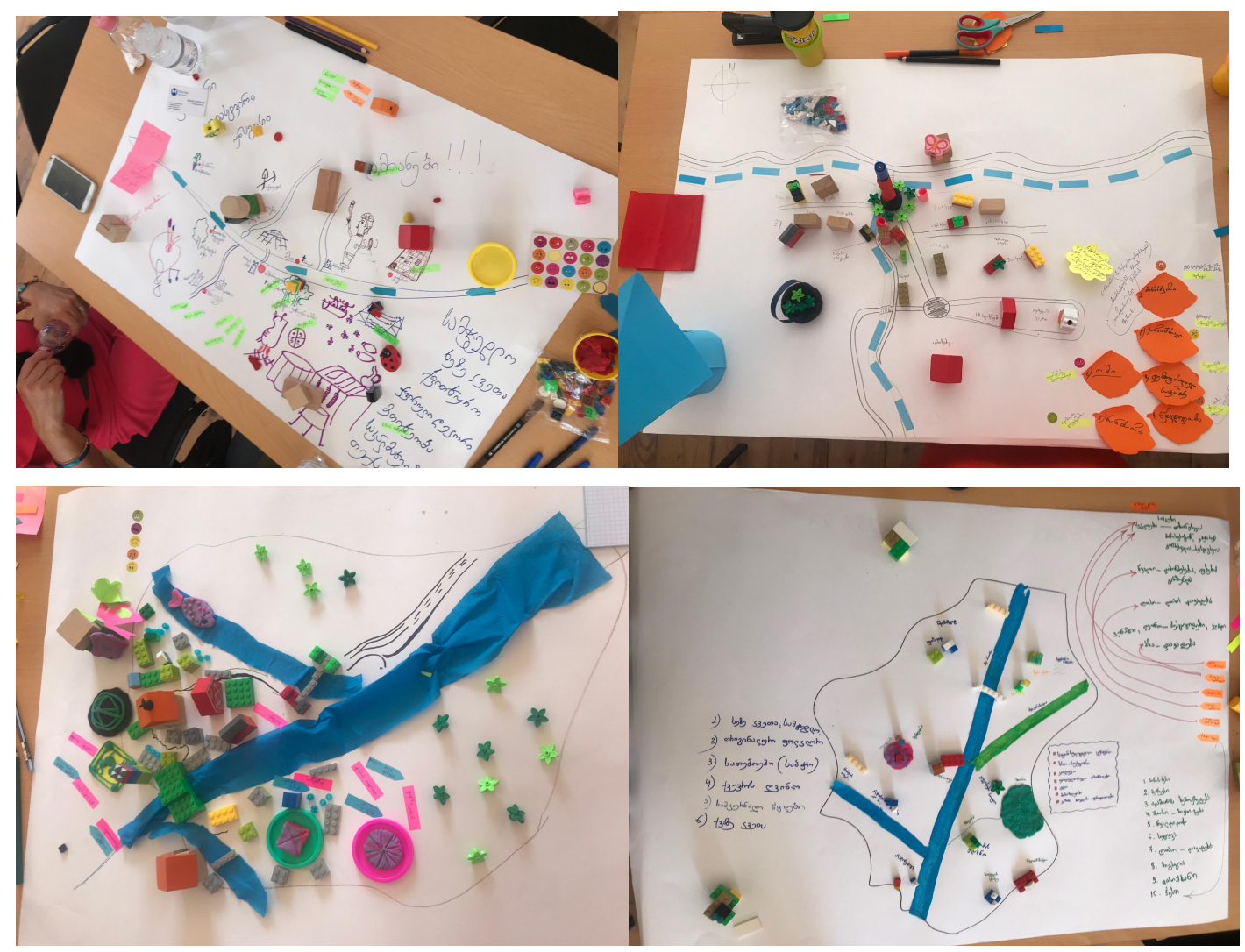

Figure 3 Examples of maps developed by different groups

The second stage of data collection focused on decision-making and prioritisation. The selected participants (who nominated themselves) from each group were invited for the final workshop thus creating a mixed group of people, including 9 participants ( 4 male and 5 female) representing all the groups that were involved in the first stage. They were asked to decide which cultural heritage in their region is the most important because it increases capacities, and which are the most salient risks that need addressing in order to protect this cultural heritage. The prioritisation has been carried out in three steps:

1. The list of 16 tangible cultural heritage sites/ objects, 8 intangible cultural heritage elements, 7 natural heritage sites, 11 risks, and 8 strengths (all informed by the findings of the first stage of the research) were given to each participant. They were then asked to individually choose 5 top listings in each category that they would like to be considered for the next step;

2. The participants were divided into two groups, and were asked to compare their lists and create a new list of priorities that comprises 4 top listings in each category;

3. Finally, all participants together were asked to discuss 3 top listings in each category.

The prioritised cultural heritage sites, objects and elements as well as capacities were then used to co-create a five-step action plan that will be taken forward by the community (the discussion of the plan is however outside the scope of this paper).

Each discussion was recorded in Georgian and thematically analysed. Thematic analysis was chosen due to the complexity of the dataset and the need for a flexible analytical process to provide a structure (Howitt and Cramer, 2011). The key themes were then translated into English and discussed among all the co-authors.

\section{Results and discussion}

\subsection{Cultural heritage that matters}


A diverse range of tangible, intangible and natural heritage was mapped out by the groups. Unsurprisingly, different groups focused on different elements: for instance, farmers and wine makers largely focused on natural heritage, whereas craftspeople emphasised traditions and skills; all groups also mapped out vernacular architecture and churches. These categories will be now described and discussed in more detail.

\subsubsection{Tangible heritage}

Religious building and sites have been mapped out by every group; these included churches (e.g. Church of Zemo Krikhi, Church of the Holy Virgin in Ghebi, Church of the Holy virgin in Utsera, Church in village Sori, Mravaldzali church, Qolosi church in village Shkmeri, Barakoni church (and the icon that it has), Nikortsminda church, Church ruins in village Chordi, Churches ruins in Bari village), Oni synagogue, and a monastery complex. In many cases, the importance of the emotional connection rather than the architectural value was mentioned (this will be discussed further in section 5.4).

Vernacular architecture was also prominent: wooden houses, towers and fortified dwellings were mapped as heritage. Tower houses - 'Duroiani Sakhli' (Fig.4) are a specific typology of a vernacular architecture typical of the Upper Racha region. In these houses, the livestock would live on the ground floor and the family would live on the upper floor. Many of these houses were destroyed in the 1991 earthquake, and the only tower that survived is now dilapidated, as it was not managed properly. Fortified dwellings were common in Racha; in times of war, they served both military and shelter purposes. Interestingly, the participants mapped out some objects and places that would not be typically considered as 'heritage'; for instance, a library and a community centre were placed on the map.

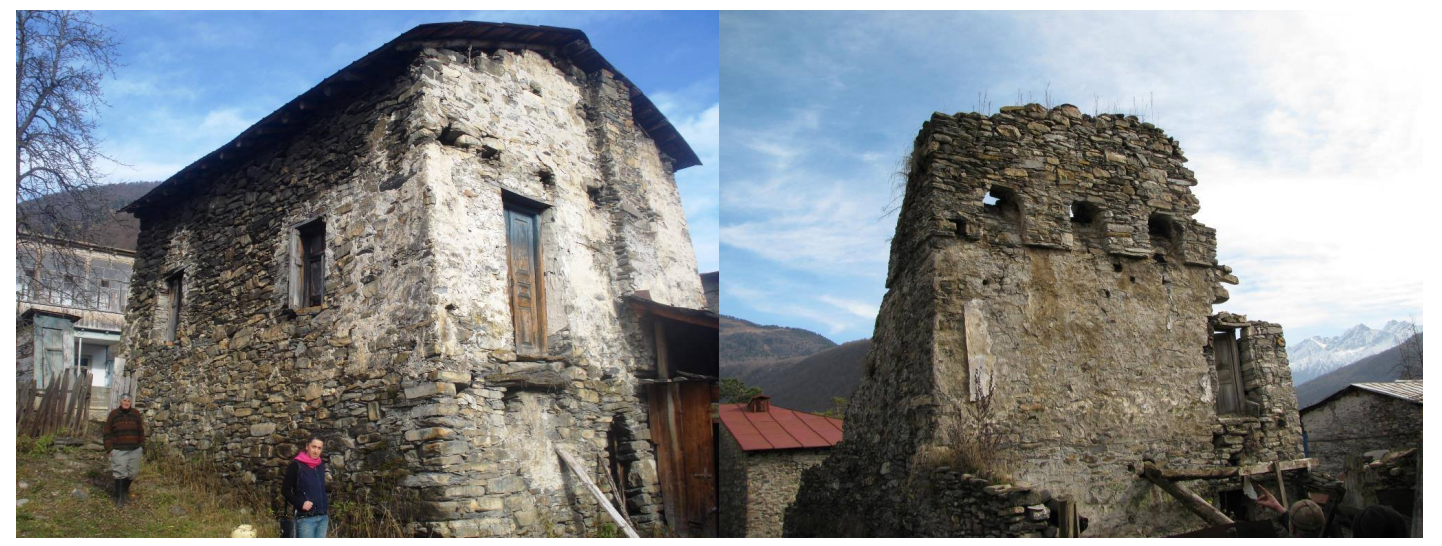

Figure 3 The Ghebi Tower House "Duroiani Sakhli" (source: @ Natia Maisashvili, 2010)

Craft-related materials and objects (e.g. wood, stone) and places (e.g. wine cellars) were mapped out, although the participants in some groups noted that many of the traditional skills and practices are not pursued. For instance, wooden wine pressers are now hardly used as making them requires a large chestnut tree trunk; these are a rare find, as the Government does not allow woodcutting in the region. This policy affects the wood carving too, with craftspeople forced to reuse the wood that they already have. All these elements are again closely connected to capacities that these communities have.

\subsubsection{Intangible heritage}

Culinary and wine making: Given that the region is famous for its wine, it was not surprising that many participants mapped out wine making; it is part of many livelihoods in this area. Traditional culinary practices (e.g. lobiani, ham, bread-making) were also considered important; many of the traditions are grounded in not just the cooking techniques but in husbandry and viticulture. 
Crafts, such as wood and stone carving as well as blacksmithing, were prominent on the maps; however the participants agreed that many of the skills are disappearing due to the lack of interest to learn these skills among the younger generation (this will be discussed in more detail in section 4.2) as well as because of the governmental programmes are not tailored to the local characteristics.

Traditional social activities related to various festivals and occasions as well as to daily life were also salient. Traditional folk songs, music and dance were mapped out, however many participants pointed out that these - similarly to the craft skills - are gradually being lost. Sanakhsho - 'a meeting of the elders' - where people tend to exchange information, sing songs and generally communicate was seen as an important part of daily life and the main source of community spirit.

\subsubsection{Natural heritage}

Many of the natural heritage elements were closely connected to the intangible heritage elements. For instance, connected to the craft of wine making, the microzone of Khvanchkara was perceived as an important element of the natural heritage as it provides locals with the opportunity to grow grapes and produce the famous Georgian Khvanchkara semi-sweet red wine.

Similarly, rivers, forests and caves were considered important. The local awareness of the behaviour of natural heritage was also seen as a way to manage risks (e.g. certain behaviour in the river warned people in lower Racha about flooding in Upper Racha). However, some participants have noted that recent changes in the nature protection legislation have hindered their ability to use these resources for crafts. Combined with de-population of the area, the expansion of the forest has also led to threats from wild animals (e.g. bears have been seen on the roads, and some of the local people fear for their cattle).

\subsection{Cultural heritage and risks, vulnerabilities and the root causes}

\subsubsection{Natural hazards}

As described in Section 2, the region is prone to various natural hazards; most of these (including earthquakes, flooding, landslides) have been mapped out by the participants. All participants were aware that the 'next big earthquake' will come at some point, and that climate change has an impact on the amount of precipitation in the region and the change in weather patterns (which, in turn, affects wine growing). However natural hazards are perceived as a part of their existence, a process they have been living with and are aware of - and thus prepared for. It was not clear how such preparedness manifests itself in, for instance, construction, however it appeared that the role of social ties plays an important role (and will be discussed in section 5.3).

\subsubsection{Vulnerabilities and its root causes}

In order to understand the role of cultural heritage in increasing vulnerabilities of the local people, we wanted to capture what and who are vulnerable, as well as the root causes of these vulnerabilities. However, given the contested and malleable (as well as not easily translatable and understandable) nature of the term 'vulnerability', we decided to avoid using it. Instead the facilitators asked various questions (that differed from group to group) to understand what the root causes are and how they are evolving in time and space. The following elements have been emphasised on the maps:

Demographic situation appeared to be the main concern of all the groups. The migration to urban areas results in a gradual loss of 17-40 age group, as young people go study in cities and do not return. In some villages there are now 10-15 children in the schools, where in the 1980s there used to be around 800 students. The government has recently started to encourage 
people to move back to the rural area, however the incentives are neither sufficient nor tailored and the access to social and cultural assets are limited. The participants, for instance, discussed a recently introduced 'Produced in Georgia' programme aimed at supporting local small businesses. Under the programme's conditions, the farmers should have at least 3 hectares in order to receive the grant, but people in Racha wouldn't usually have that much land. Moreover, not everyone had an ability to write a grant proposal to apply for a programme. For successful applications, the participants were obliged to take part in the training sessions that were sometimes held in Tbilisi located over $400 \mathrm{~km}$ away, meaning that successful applicants would have to spend their own money and time on travelling; many felt that it was not worth it. Moreover, the current political situation affected by the GeorgianRussian relationship does not benefit the region. Many of the participants used a term 'creeping occupation' manifested through fencing along the administrative boundary lines; this has an adverse effect on the rights of local residents, who are gradually losing access to their orchards, pasture and farmland.

Regional development is much needed as the area is isolated due to poor road access and poorly maintained infrastructure. The construction of the dams and reservoirs for hydropower was also noted on many maps: the project is privately financed, it aims to build a cascade of dams and reservoirs for a hydropower station and could increase the investment in road infrastructure and create local jobs thus attracting back some of the younger population. At the same time, however, the participants felt that this project would affect the microclimate that is critical for vineyards.

All of these are affecting intangible heritage and consequently, reducing local people's livelihood strength, wellbeing, and social protection - and resulting in an increased vulnerability. Here, cultural heritage plays into increasing vulnerability as there is a deep attachment to the place and tradition. The main concern among the locals about the impact of natural hazards was reflective of that: if the churches and vineyards are destroyed, what would be there left to live for?

\subsection{Cultural heritage and capacities}

The original aim of the research was to identify the role of cultural heritage in coping with and adapting to natural hazards. However, as the data collection unfolded, two things became clear: local participants are much more concerned about root causes of disasters, and that the relationship between capacities and cultural heritage were not immediately identified by the participants.

Cultural heritage is seen as an important contributor to the economic capacities (Throsby, 2012). In Racha, a multitude of ancient churches, holy relics and the inseparable mix of religious and natural heritagescapes, attracts many domestic and international tourists (Metreveli and Timothy, 2009). This is intertwined with the intangible heritage: vineyards bring people to the region, and there are many guesthouses. Tourism also encourages younger people to learn traditional music and dance, thus helping to keep the tradition. But there is more to it.

Traditional practices established in the community are accepted and integrated with broader cultural traditions; these are seen as an important part of social assets. For instance, the 'sanaksho' (social gathering) is an important part of life as it provides an opportunity for an informal exchange of information as well as the preservation of traditional song and dance. The sense of having a shared experience and facing similar challenges also ties these communities together: many participants talked about the sense of patriotism that is the key motivator for not leaving this region and its traditions.

\subsubsection{Prioritising cultural heritage}


As described in section 4, we also explored how different communities prioritise various heritage elements and their role in increasing capacities as well as the risks that may affect this cultural heritage (Table 1). This prioritisation was important as it allowed to facilitate the discussion that connected cultural heritage with capacities (highlighting that, for instance, folklore is not just a source of economic resources but also an important aspect of social ties that become critical in a disasters) - and what risks could affect these capacities, showing that these are often enhanced through the spatially and temporally removed decisions that impact cultural heritage as an unintended consequence.

Table 1 The most salient priorities agreed upon by the group

\begin{tabular}{|l|l|l|l|}
\hline \multicolumn{2}{|l|}{ Cultural heritage } & $\begin{array}{l}\text { What are the key risks } \\
\text { that affect CH? }\end{array}$ & $\begin{array}{l}\text { What are the key } \\
\text { elements that make } \\
\text { livelihoods stronger } \\
\text { (i.e. the role of CH in } \\
\text { capacities)? }\end{array}$ \\
\hline Tangible & $\begin{array}{l}\text { Traditional homes "duroiani } \\
\text { sakhli") } \\
\text { Bugeuli } \\
\text { Minda tsikhe }\end{array}$ & $\begin{array}{l}\text { Migration } \\
\text { Earthquake } \\
\text { Folklore } \\
\text { Wine making and cuisine } \\
\text { infrastructure }\end{array}$ & $\begin{array}{l}\text { Tourism } \\
\text { Strong social ties }\end{array}$ \\
\hline Intangible & $\begin{array}{l}\text { Mineral water springs; } \\
\text { Cave; } \\
\text { Micro-zone of wine }\end{array}$ & & \\
\hline
\end{tabular}

Prioritising tangible cultural heritage proved to be the hardest: as the participants represented two towns, they wanted their sites to be listed. In the end the decision was taken to map two churches (one in each region), yet for a while the group could not agree on the third listing. In the intangible heritage category, the participants agreed to merge wine making and cuisine into the same category as the participants felt that they are closely intertwined. The natural heritage category was easiest to agree upon: here the participants shared their opinions and could easily relate and explain the importance of each site.

What these exercises highlighted is the difficulty to ensure that everyone's view on cultural heritage is included. This becomes particularly problematic when many interest groups are represented. Practical shift towards inclusion requires trade-offs at multiple levels, between and among various sectors and sections of the community and their representatives. But the first step in achieving these trade-offs lies in the understanding of the role of cultural heritage in increasing and decreasing vulnerabilities and capacities of different communities and individuals within them. The discussion around risks and capacities flowed much easier than the establishment of cultural heritage priorities. Regardless of the elements, the challenges related to their protection - and the consequential impacts on capacities - were similar.

What the mapping and the prioritisation exercises highlighted is that the links between the vulnerabilities and capacities and the heritage elements are not immediate or obvious. This 
demonstrates that, whilst often being part of daily life, the role of heritage in coping with disaster risks is not explicit. Given that heritage not only gives identity to community, but also makes direct and significant contribution to sustainable development, it is important that the communities understand better how heritage could potentially contribute to enhancing capacities. But it is also important to see cultural heritage elements as sources of vulnerabilities. Here migration and failed infrastructure are seen as processes that reduce people's ability to look after cultural heritage. The participants highlighted that if the traditions of winemaking, woodcraft, song and dance, cooking are lost, the identity of the region will also be lost.

Moreover, policy decisions that are not explicitly relevant to cultural heritage further increased vulnerability of some groups of the population. An example of the wood cutting ban described in the earlier sections had major implications for craftspeople as well as on housebuilding and wine making practices that are at the heart of the people's capacities. Here a blanket policy approach addressed an immediate issue but did not consider unintended consequences; this could be avoided if more voices are heard.

\section{Conclusions}

This paper explored the views of the local population on their cultural heritage and its role in contributing towards vulnerabilities and capacities. We wanted to engage with the local communities in order to provide a reflective place for the conversation that would lead to the development of a process, through which people realise by themselves the extent, strength and diversity of their individual and collective capacities that are embedded in heritage - and how these can be maximised when facing hazards.

In the beginning of the paper, we noted a question: do culture and heritage exacerbate vulnerabilities or provide a source of strength? The answer is - both. The participatory mapping exercise highlighted that cultural heritage cannot be seen in an exclusive manner devoid of its larger environmental, political, social and economic contexts. Heritage is an inherent part of human identity that is closely intertwined in day-to-day lives of people. It plays a role in sustainable development and DRR, but for the local communities this role is not primary or explicit, and neither is it static; rather it is continuously evolving in response to changes, including those induced by disasters, and the context in which the disasters occur.

We need more understanding of the role of cultural heritage in enhancing capacities. Whilst heritage is becoming more fragile, the maintenance of traditional practices has been and remains to be at the core of the people's social capacities. Tangible and intangible dimensions are intertwined; the activities aimed to support intangible heritage would ensure the sustainability of tangible heritage. The loss of tangible and intangible cultural heritage can affect cultural and social values. But many DRR efforts are directed at the tangible manifestations of heritage at the expense of the intangible - thus often increasing vulnerabilities. This would also necessitate efforts towards addressing root causes of social and economic vulnerability of those communities who are true bearers of heritage. Cultural heritage, capacities and vulnerabilities are intertwined; this is manifested in particular in the role that intangible heritage plays in people's lives - but we need more understanding of these interconnections.

Enhancing capacities does mean that vulnerabilities, rooted in political decisions, social systems and distribution of power, are addressed. Deeper understanding of the cultural heritage through the eyes of the local people, who live with and within cultural heritage and to whom it is a part of daily life, is thus important if we are to understand its role in reducing vulnerabilities and enhancing capacities - and the trade-off that are required. 
Acknowledgements: This work has been conceived within the framework of ICCROM's flagship programme on First Aid and Resilience for Cultural Heritage in Times of Crisis, and its capacity building project on Culture Cannot Wait: Heritage for Peace and Resilience, supported by the Swedish Postcode Foundation. The authors thank the organising partners, Blue Shield Georgia, for the local organisation and workshop facilitation; all participants for giving us their invaluable time and local organisers - Centre for Adult Learning, where we conducted the first round of exercises, and the Razmadze family in whose garden conducted the final exercise.

\section{References:}

Arunotai, N. 2008. Saved by an old legend and a keen observation: the case of Moken sea nomads in Thailand. In: R. Shaw, N. Uy and J. Baumwoll (eds.), Indigenous knowledge for disaster risk reduction: good practices and lessons learnt from the Asia-Pacific region. UNISDR Asia and Pacific, Bangkok, pp.73-78.

Bankoff, G., 2001. Rendering the World Unsafe: 'Vulnerability' as Western Discourse. Disasters, Vol. 25, Issue 1: 19-35.

Boccardi, G. and Duvelle, C. (2013), "Cultural Heritage and Sustainable Development: A Rationale for Engagement", available at: http://www.unesco.org/new/fileadmin/MULTIMEDIA/HQ/CLT/images/HeritageENG.pdf (accessed 16 Sept. 2020).

Cadag, J. and Gaillard, JC., 2014. Integrating people's capacities in disaster risk reduction through participatory mapping. In: Lopez-Carresi, A., Fordham, M., Wisner, B., Kelman, I. and Gaillard, JC (eds.), Disaster Management: International lessons in reduction, response and recovery. London: Routledge. Ch.17, pp. 269-86.

Cannon, T. (2008). Reducing people's vulnerability to natural hazards: Communities and resilience. Research Paper No. 2008/34. Helsinki, Finland: WIDER.

Chambers, C., 2017. Can we know better?? Reflections for development. Rugby: Practical Action Publishing Ltd.

Chinyele, J. B. \& Lwoga, N. B. (2019). Participation in decision making regarding the conservation of heritage resources and conservation attitudes in Kilwa Kisiwani, Tanzania. Journal of Cultural Heritage Management and Sustainable Development. Vol.9 (2) (pp.184189). ISSN 2044-1266.

Chmutina, K., Jigyasu, R. and Okubo, T., 2019. Securing future of heritage by reducing risks and building resilience. Disaster Prevention and Management, 29 (1), 1-9.

Crabtree, A. (2015). The deep roots of nightmares. In F.Kruger, G.Bankoff, T. Cannon, B. Orlowski \& E. L. Schipper (Eds.), Cultures and Disasters: Understanding Cultural Framings in Disaster Risk Reduction (pp.155-173). Oxon, New York: Routledge.

Daisuke, S. (2020). Psychosocial Support and History: How Preserving Heritage can Rebuild Communities. In J. F. Morris (Ed.), History, Heritage, and Resilience : Case Studies in Saving Historical Heritage as Psychosocial Support (pp. 1-9). Sendai: Tohuku University.

Daly, P. \& Winter, T. (2012). Converging Forces, Conflicting Values. In P. Daly \& T. Winter (Eds., Routlegde Handbook of Heritage in Asia (pp.16-17). Oxon, New York: Routledge.

Directorate-General for Communications Networks, Content and Technology, European Commission. (2019). Creative Europe: Monitoring Report 2018 (p.8). Belgium: Imprimerie Bietlot. 
Gaillard, JC; Hore, K. and Cadag, J R D. Participatory mapping for disaster risk reduction: A review. The Globe, 76, pp. 31-38'

Georgia Red Cross, Small Scale Mitigation Projects Case Study. http://drrsouthcaucasus.org/uploads/files/DRRIII_SSMP_Case_Study_v3.pdf (accessed 13 July, 2020)

GFDRR, $2015 . \quad$ Georgia. Available at: http://pubdocs.worldbank.org/en/289611483041846865/georgia.pdf (accessed 16 Sept. 2020)

Hoije, K. (2014, October 22). Mali's Griots See a Role in the Peace Process. Available at: https://www.voanews.com/africa/malis-griots-see-role-peace-process (last accessed: 16 Sept. 2020).

Howitt, D. and Cramer, D. 2011. Introduction to Research Methods. Pearson, UK.

IBP, Inc (2012) Georgia Country Study Guide Volume 1 Strategic Information and Developments. p.28, p.190.

Isar, Y.R. (2011). UNESCO and Heritage: Global Doctrine, Global Practice. In H. Anheier \& Y.R. Isar (Eds.), The Cultures and Globalization Series 4: Heritage, memory \& identity (pp. 3951). London: SAGE Publications Ltd.

Jigyasu, R. (2016), "Reducing Disaster Risks to Urban Cultural Heritage: Global Challenges and Opportunities", Journal of Heritage Management, Vol. 1, Iss.1, pp. 59-67.

Jones, L. and Boyd, E., 2011. Exploring social barriers to adaptation: Insights from Western Nepal. Global Environmental Change, 21 (4), 1262-74.

Kohler, T., Elizbarashvili, N., Meladze, G., Svanadze, D., and Meessen, H., 2017. The Demogeographic Crisis in Racha, Georgia: Depopulation in the Central Caucasus Mountains. Mountain Research and Development, 37(4), 415-24

Langenbach, R., (2009), Don't tear it down!: Preserving the earthquake resistant vernacular architecture of Kashmir, UNESCO, published by Oinfroin Media, Oakland

Lavigne, F., De Coster, B., Juvin, N., Flohic, F., Gaillard, JC., Texier, P., Morin, J., Sartohadi, J., 2008. People's behaviour in the face of volcanic hazards: Perspectives from Javanese communities, Indonesia. Journal of Volcanology and Geothermal Research, 172, pp 273-287

Lloyd, G. (2012). Legislating to Safeguard Asia's Intangible Heritage. In P. Daly \& T. Winter (Eds., Routlegde Handbook of Heritage in Asia (pp.139-143). Oxon, New York: Routledge.

Metreveli, M. and Timothy, D.J., 2009. Religious heritage and emerging tourism in the Republic of Georgia. Journal of Heritage Tourism, 5 (3), 237-44.

Miichi, K., 2016. Playful relief: folk performing arts in Japan after the 2011 tsunami. Asian Ethnology, 75(1), pp.139-62.

Pareek, A. and Trivedi, P.C., 2011. Cultural values and indigenous knowledge of climate change and disaster predictions in Rajasthan, India. Indian Journal of Traditional Knowledge, 10 (1), pp.183-9.

Pelling, M. (1998), "Urban flooding in Guyana”, Journal of International Development, Vol. 10, pp. 469-86.

Protection of Internally Displaced Persons in Georgia: A Gap Analysis (2009)

Racha Lechkhumi and Lower Svaneti Development Strategy 2014-2021 (2013).

http://gov.ge/files/275_38379_941560_137419.09.13\%E2\%80\%931.pdf(accessed 16 Sept.

2020, 2020) 
Schipper, E.L., (2015). Religion and Belief systems: drivers or vulnerability, entry points for resilience? In F.Kruger, G.Bankoff, T. Cannon, B. Orlowski \& E. L. Schipper (Eds.), Cultures and Disasters: Understanding Cultural Framings in Disaster Risk Reduction (pp.145-153). Oxon, New York: Routledge.

Simpson, M. (2018). Heritage: Non-Western Understandings. In S.L. López Varela (Ed.), The Encyclopedia of Archaeological Sciences. doi:10.1002/9781119188230.saseas0300

Singh, K. (2015). Museums, Heritage, Culture: Into the Conflict Zone. In R. Knoop, J. Bemont and Pauline van der Pol (Eds.), The Reinwardt Memorial Lectures (pp.29-54). Amsterdam: Reinwardt Academy, Amsterdam University of the Arts.

Smith, L. (2006). Uses of Heritage (pp. 29-35). London: Routledge.

Smith, L. (2015). Intangible heritage: a challenge to the authorised heritage discourse, Ethnologia, 40, pp. 133-142.

Throsby, D., 2012. Economic Impacts of Cultural Heritage Projects in FYR Macedonia and Georgia. The World Bank. Urban Development Series Knowledge Papers No 16. Available at: https://openknowledge.worldbank.org/bitstream/handle/10986/17386/NonAsciiFileName0. pdf?sequence=1 (accessed 16 Sept. 2020).

Titumir R.A.M., Afrin T., Islam M.S. (2020) Traditional Knowledge, Institutions and Human Sociality in Sustainable Use and Conservation of Biodiversity of the Sundarbans of Bangladesh. In Saito O., Subramanian S., Hashimoto S., Takeuchi K. (Eds.), Managing Socioecological Production Landscapes and Seascapes for Sustainable Communities in Asia. Science for Sustainable Societies. Singapore: Springer.

Topchishvili R. (2010) Ethnography of Georgia pp. 126-128

UNESCO (2017), World Heritage Convention and Sustainable Development, $\mathrm{WHC} / 17 / 41 . \mathrm{COM} / 5 \mathrm{C}, \quad$ available at: https://whc.unesco.org/archive/2017/whc17-41com-5C-en.pdf (accessed 16 Sept. 2020).

UNESCO (n.d.). The UNESCO Cultural Conventions: a tool for sustainable development. Available at: http://www.unesco.org/new/en/culture/themes/culture-anddevelopment/the-future-we-want-the-role-of-culture/the-unesco-cultural-conventions (last accessed: 167 Sept. 2020)

UNESCO (n.d.). The World Heritage Convention. Available at: https://whc.unesco.org/en/convention/ (last accessed: 16 Sept. 2020)

UNESCO (n.d.). Cultural Landscape and Archaeological Remains of the Bamiyan Valley. Available at: https://whc.unesco.org/en/list/208/ (last accessed: 16 Sept. 2020)

UNDP, 2014. Georgia. Disaster risk reduction capacity assessment report. Available at: https://www.cadri.net/sites/default/files/GEORGIA-DRR-Capacity-Assessment-Report.pdf (accessed 16 Sept. 2020)

UNDP, 2018. Georgia: Human development indicators. Available at: http://hdr.undp.org/en/countries/profiles/GEO (accessed 16 Sept. 2020)

UNHRC. (2016). Resolution adopted by the Human Rights Council on 30 September 2016. A/HRC/RES/22/30. New York: UNHRC.

UNSC. (2017) Resolution 2347(2017) Adopted by the Security Council at its 7907th meeting, on 24 March 2017. S/RES/2347 (2017). New York: UN Security Council. 
Varazanashvili, O., Tsereteli, N., Amiranashvili, A., Tsereteli, E., Elizbarashvili, E., Dolidze, J., Qaldani, L., Saluqvadze, M., Adamia, S., Arevadze, N. and Gventcadze, A. 2012. Vulnerability, hazards and multiple risk assessment for Georgia. Natural Hazards, 64 (3), 2021-56.

Weiss, G. \& Connelly, N. (2017). Cultural Cleansing and Mass Atrocities: Protecting Cultural Heritage in Armed Conflict Zones. Issue 1 of J. Paul Getty Trust Occasional Papers in Cultural Heritage Policy. Los Angles: J. Paul Getty Trust

Winter, T. (2007). Post-conflict heritage postcolonial tourism: Culture, politics and development at Angkor. Oxon, New York: Routledge.

Wisner, B., 2016. Vulnerability as concept, model, metric, and tool. In: Cutter SL (ed) Oxford research encyclopedia: natural hazard science. Oxford University Press, Oxford.

The World Bank, Middle East and North Africa Region (2001). Cultural Heritage and Development: A Framework for Action in the Middle East and North Africa Region. Orientations in Development Series (pp. 30-31). Washington, DC: The World Bank

World Bank Group, (2016) GEORGIA: RECENT TRENDS AND DRIVERS OF POVERTY REDUCTION http://pubdocs.worldbank.org/en/980951472223098077/Georgia-PPA-FY16-presentationAUG2016-final.pdf (accessed 16 Sept. 2020) 